\title{
Metacercárias de Ascocotyle (Phagicola) longa Ransom, 1920 (Digenea: Heterophyidae), em Mugil platanus, no estuário de Cananéia, SP, Brasil
}

\author{
Ascocotyle (Phagicola) longa Ransom, 1920 (Digenea: Heterophylidae) metacercariae, in Mugil platanus \\ in estuarin of Cananéia, SP, Brazil
}

\author{
Sandra Aparecida de Oliveira ${ }^{\mathrm{I}}$ Francisco Javier Hernandez Blazquez ${ }^{\mathrm{II}}$ Sergio Araújo Antunes ${ }^{\mathrm{I}}$ \\ Antonio Augusto Mendes Maia ${ }^{\mathrm{I}}$
}

\section{RESUMO}

Estudou-se no estuário de Cananéia, litoral do estado de São Paulo, Brasil, a presença de Ascocotyle (Phagicola) longa Ransom, 1920 (Digenea: Heterophylidae), trematódeo, em tainha (Mugil platanus, Günther, 1880). Foram realizadas amostragens a fresco e cortes histológicos em tecidos provenientes de 61 exemplares. A presença de metacercárias foi comprovada em $100 \%$ dos peixes examinados, com a seguinte distribuição: coração (21,6\%), fígado $(19,7 \%)$ e rins (58,6\%). As alterações histológicas no tecido cardíaco foram caracterizadas pela presença de um granuloma parasitário formado por uma cápsula de tecido conjuntivo ao redor do parasita, levando a um edema generalizado. Para determinar a infecção em alevinos de tainha da espécie M. platanus, foram capturados 100 exemplares nas entradas de córregos da região estuarino-lagunar. Esses peixes foram eviscerados para a pesquisa de metacercárias pelo exame a fresco, verificando-se que $100 \%$ dos alevinos não estavam infectados.

Palavras-chave: Mugil platanus, Ascocotyle (Phagicola) longa, metacercária, histopatologia.

\section{ABSTRACT}

The present research was carried out the coast of the state of São Paulo, Brazil, when it was studied the presence of Ascocotyle (Phagicola) longa Ransom, 1920 (Digenea: Heterophylidae), trematode, in mullet (Mugil platanus, Günther, 1880). Fresh samples and histological tissues sections from 61 animals were obtained. The results showed presence of metacercariae of A. (P.) longa in $100 \%$ of the fish examined, with the following distribution: heart (21.6\%), liver (19.7\%) and kidneys (58.6\%). Histological alterations in cardiac tissues were characterized by the presence of a parasitic granuloma formed by a connective tissue capsule around the parasite, leading to generalized edema. To determine the infection in juvenile grey mullets of the M. platanus species, 100 of them were captured in the stream entrances of the estuary region, each fish was individually sacrificed and fresh mounts were prepared to determine the presence of metacercariae, demonstrating that $100 \%$ of the juveniles were not infected.

Key words: Mugil platanus, Ascocotyle (Phagicola) longa, metacercariae, histopathology.

\section{INTRODUÇÃO}

A tainha Mugil platanus ocorre em águas tropicais e subtropicais de vários países do mundo, principalmente nas áreas costeiras e estuarinas, sendo considerada fonte de proteínas para alimentação humana (MENEZES, 1983).

Esses peixes representam uma das grandes alternativas para a aqüicultura brasileira, pois as suas características biológicas garantem grande potencialidade para criação em água salobra, doce ou salgada (ANTUNES \& ALMEIDADIAS, 1994). Nessas condições, os peixes podem estar parasitados por larvas de vários trematódeos (ALMEIDA DIAS, 1997), inclusive a $\boldsymbol{A}$. (P.) longa, agente de uma importante zoonose. No Brasil, nas cidades de Cananéia e Registro, foi verificado que, de 102 pessoas que consumiram tainha crua, $8,82 \%$ estavam infectadas pelas formas adultas do parasita (CHIEFFI et al., 1990; CHIEFFI et al., 1992; ALMEIDADIAS \& WOICIECHOVSKI, 1994).

As aves aquáticas ictiófagas podem ser consideradas os hospedeiros definitivos mais importantes (SARAIVA, 1992), uma vez que freqüentam

'Departamento de Ciências Básicas, Faculdade de Zootecnia e Engenharia de Alimentos, Universidade de São Paulo (USP), Pirassununga, SP, Brasil.

"Departamento de Cirurgia, Faculdade de Medicina Veterinária e Zootecnia, USP. Avenida Duque de Caxias Norte, 225, 13635-900, Pirassununga, SP, Brasil. E-mail: maia@fzea.usp.br. Autor para correspondência. 
coleções de água onde existe abundância de caramujos da espécie Hastula cinerea, considerados os prováveis primeiros hospedeiros intermediários deste parasita (ALMEIDA DIAS, 1997). No ciclo do parasita, o segundo hospedeiro intermediário é representado por mugilídeos. Metacercárias de A. (P.) longa, Ransom, 1920 (Digenea: Heterophyidae) foram também identificadas no Brasil na espécie M. platanus (GODINHO et al., 1988; KNOFF et al., 1997).

A prevalência da $\boldsymbol{A}$. (P.) longa em tainhas de águas peruanas foi estudada por ARMAS DE CONROY (1979), com 72,5\% das metacercárias encontradas no coração, fígado e mesentério. $\mathrm{Na}$ Venezuela, SARAIVA (1992) encontrou-as em 92,5\% dos corações examinados. ANTUNES \& ALMEIDA DIAS (1994), no litoral de Santos, Estado de São Paulo, encontraram $100 \%$ de tainhas parasitadas, sendo os órgãos mais acometidos o coração, o fígado e o tecido muscular. RANZANI-PAIVA (1995) registrou, nas amostras de fígado examinadas a fresco, $50 \%$ de cistos. KNOFF et al. (1997), no litoral do Rio de Janeiro, Estado de Rio de Janeiro, encontraram uma prevalência de $35.3 \%$ de A. (P.) longa em M. platanus. Assim podemos observar que a prevalência da $\boldsymbol{A}$. (P.) longa é alta em várias regiões em que o parasita foi estudado.

Os objetivos do trabalho foram: estudar a ocorrência de metacercárias de $\boldsymbol{A}$. (P.) longa em exemplares de $\boldsymbol{M}$. platanus capturados na região estuarina de Cananéia, no Estado de São Paulo, as principais alterações histológicas decorrentes do parasitismo e a distribuição dessas larvas nos tecidos.

\section{MATERIAL E MÉTODOS}

Sessenta e um exemplares de tainha com comprimento total médio de $42 \pm 7 \mathrm{~cm}$ e peso médio de $971 \pm 120$ gramas foram capturados na região de Cananéia, Estado de São Paulo, durante o período de Abril de 2000 a Outubro de 2001, sendo esses peixes identificados segundo MENEZES (1983) e MENEZES \& FIGUEIREDO (1985). Cada exemplar foi eviscerado, retirando-se os tecidos e órgãos como coração, fígado, rins, baço, músculo cranial e músculo caudal. O exame a fresco para a pesquisa das metacercárias foi realizado utilizando um microscópio óptico, segundo a metodologia proposta por ANTUNES \& ALMEIDA DIAS (1994).

Para verificar a distribuição das metacercárias, dez exemplares adultos foram eviscerados, sendo colhidas amostras de coração, fígado e rins, que foram fixadas em solução de Bouin (70\% de solução saturada de ácido pícrico, 25\% de formol e $5 \%$ de ácido acético) por 20 horas; posteriormente, foi realizada a inclusão em parafina e realizados cortes histológicos, corados por hematoxilina e eosina.

Para determinar a infecção em alevinos de tainha da espécie M. platanus, 100 exemplares com comprimento total variando de 1,8 a $4 \pm 0,5 \mathrm{~cm}$ foram capturados nas entradas de córregos da região estuarino-lagunar de Cananéia, durante o período de $21 / 10$ de 1999 a $23 / 12$ de 2000 . Os peixes foram mantidos em condições de laboratório e, semanalmente, dez exemplares eram eviscerados para a pesquisa de metacercárias pelo exame a fresco.

\section{RESULTADOS E DISCUSSÃO}

Através dos cortes histológicos do coração, dos rins e do fígado, foi verificado que o maior número de metacercárias foi encontrado no tecido renal, com $58,6 \%$, seguido do fígado e do coração, com, respectivamente, 21,6 e 19,7\%, (Tabela 1 ).

Ao exame macroscópico das vísceras e dos tecidos infectados, não foi verificada nenhuma alteração sugestiva do parasitismo. Dessa forma, uma simples inspeção não seria capaz de identificar peixes infectados. No exame histopatológico realizado em vários órgãos como rins, fígado, coração e amostras de músculos (dados não mostrados), a metacercária foi facilmente identificada e as lesões nestes locais foram muito semelhantes. A figura 1 mostra o tecido cardíaco parasitado por uma metacercária de $\boldsymbol{A}$. (P.) longa. A reação apresenta-se como um granuloma típico, com uma cápsula de tecido conjuntivo que envolve o parasita, sendo constatada presença de células mononucleares, células musculares degeneradas e detritos celulares ao redor da cápsula do tecido conjuntivo.

FONT et al.(1984) descreveram alterações histológicas causadas por Phagicola nana em peixes da família Centrarchidae, em que as alterações histológicas são também discretas e caracterizadas por uma intensa reação fibrótica que envolve o parasita. Pequenas manchas escuras na pele foram identificadas em tainhas infectadas com A. (P.) longa (CONROY et al., 1985), mas nenhum estudo foi realizado no sentido de esclarecer estas lesões.

A elevada prevalência de metacercárias em tainhas adultas confirma os resultados de ARMAS DE CONROY (1986) e ANTUNES \& ALMEIDA DIAS (1994). Na Venezuela, SARAIVA (1992) e, na Flórida, HUTTON (1957), também registraram uma infecção em $100 \%$ das tainhas. As amostras examinadas mostram que a infecção estava presente em todos os meses em que foi realizada a pesquisa.

ARMAS DE CONROY (1986) encontrou metacercárias no coração, fígado e mesentério em $86,7 \%$ dos mugilídeos capturados no mês de novembro, e em 
Tabela 1 - Metacercárias de Ascocotyle (Phagicola) longa em cortes histológicos de coração, fígado e rins de exemplares de Mugil platanus naturalmente infectados.

\begin{tabular}{|c|c|c|c|c|c|c|}
\hline \multirow{2}{*}{ N. ${ }^{\circ}$ do peixe } & \multicolumn{3}{|c|}{ N. ${ }^{o}$ de metacercárias de $\boldsymbol{A}$. (P.) longa } & \multicolumn{3}{|c|}{ Porcentagem (\%) } \\
\hline & Coração & Fígado & Rim & Coração & Fígado & Rim \\
\hline 01 & 02 & 06 & 16 & 8,3 & 25,0 & 66.6 \\
\hline 02 & 06 & 05 & 10 & 28,6 & 23,8 & 47,6 \\
\hline 03 & 05 & 07 & 13 & 20,0 & 28,0 & 52,0 \\
\hline 04 & 06 & 09 & 18 & 18,2 & 27,3 & 54,5 \\
\hline 05 & 12 & 08 & 23 & 27,9 & 18,6 & 53,5 \\
\hline 06 & 09 & 11 & 17 & 24,3 & 29,7 & 45,9 \\
\hline 07 & 06 & 09 & 42 & 10,5 & 15,8 & 73,7 \\
\hline 08 & 07 & 09 & 21 & 18,9 & 24,3 & 56,7 \\
\hline 09 & 05 & 03 & 22 & 16,7 & 10,0 & 73,3 \\
\hline 10 & 06 & 03 & 08 & 35,3 & 17,6 & 47,1 \\
\hline Total & 64 & 70 & 190 & 19.7 & 21,6 & 58,6 \\
\hline
\end{tabular}

$11,6 \%$ no mês de agosto, indicando que houve uma variação sazonal na sua ocorrência em Cananéia. Há uma descrição de fagicolose em seres humanos (CHIEFFI et al., 1990), estando a infecção provavelmente associada com a ingestão de tainhas in natura. Este parasitismo é assintomático e caracterizado apenas por uma discreta gastrenterite (ALMEIDA DIAS \& WOICIECHOVSKI, 1994). A ausência de uma sintomatologia característica e o desconhecimento a respeito do parasita certamente contribuem para que a prevalência da fagicolose humana seja subestimada.

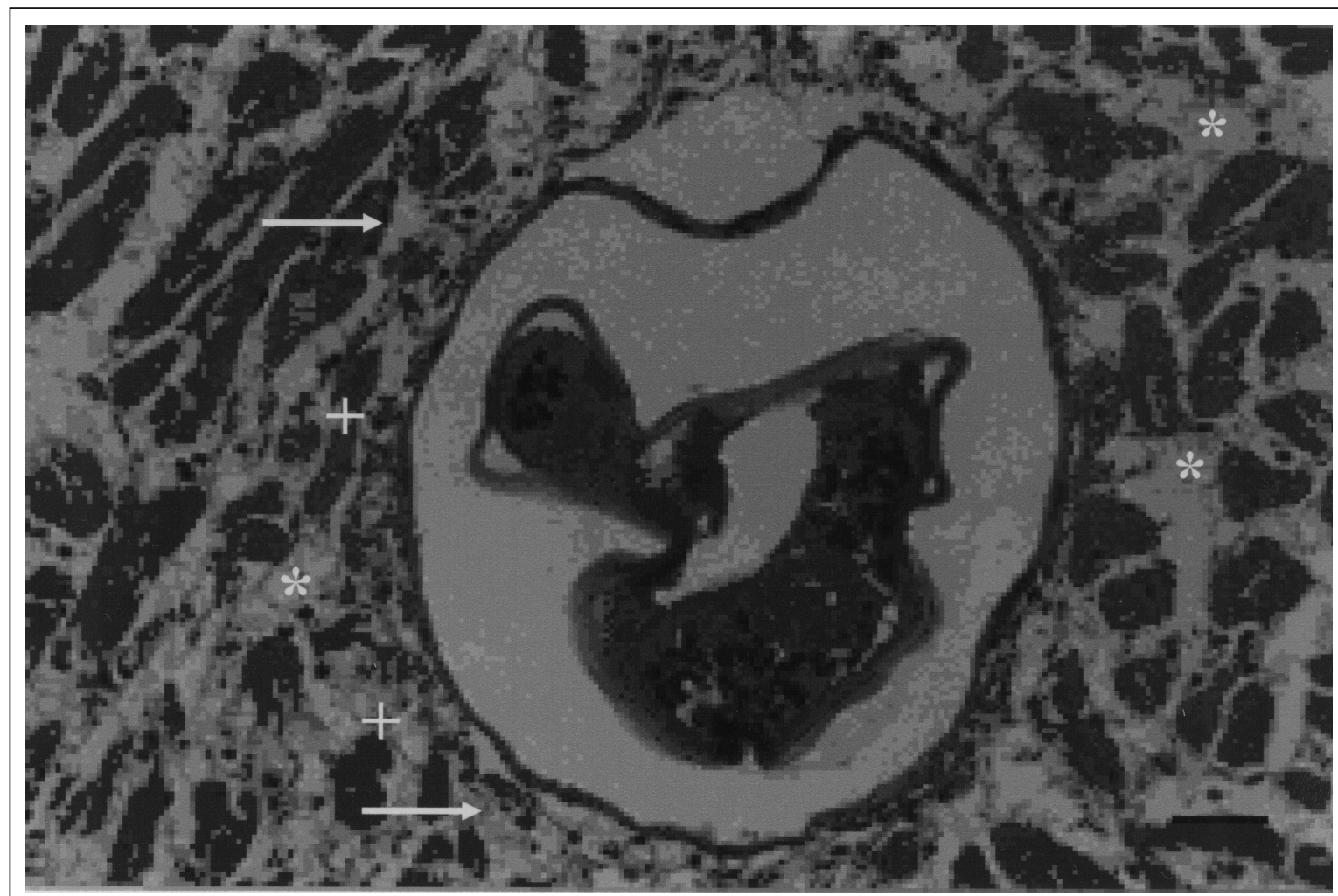

Figura 1 - Corte histológico do coração de Mugil platanus infectado por metacercária de Ascocotyle (Phagicola) longa. Células mononucleares $(\rightarrow)$, células musculares degeneradas $(+)$ e detritos celulares ao redor da cápsula do tecido conjuntivo $(*)$. Barra $=100 \mu \mathrm{m}$. Aumento $40 \mathrm{X}$. 
Quanto à distribuição de metacercárias nos tecidos de tainhas (Tabela 1), pôde-se verificar que $58,6 \%$ dos parasitas encontravam-se no tecido renal. Estes resultados diferem dos encontrados por SARAIVA (1992), que verificou $45,5 \%$ das metacercárias no coração, por RANZANI - PAIVA (1995), que encontrou 50\% no fígado e ANTUNES \& ALMEIDA DIAS (1994), que encontraram 5,26\% no tecido muscular. Não há na literatura nenhuma justificativa para a predileção das metacercárias por alguns órgãos.

Todos os alevinos examinados encontraramse isentos da infecção por $\boldsymbol{A}$. (P.) longa. Estes resultados confirmam a ausência do parasita nesta fase (CONROY et al., 1986; ALMEIDA DIAS \& WOICIECHOVSKI, 1994; ALMEIDA DIAS, 1997), sugerindo que a sua criação em cativeiro poderá assegurar a produção de peixes isentos do parasita.

Segundo ALMEIDADIAS (1997), a infecção ocorre em ambiente estuarino e em água salobra, uma vez que $60 \%$ das tainhas com 10 a $13 \mathrm{~cm}$ capturadas nestas áreas mostraram-se infectadas. Nestes locais, encontram-se os caramujos da espécie Hastula cinerea, família Terebridae (ALMEIDA DIAS, 1997), prováveis primeiros hospedeiros intermediários.

\section{CONCLUSÕES}

Com base nos estudos efetuados com tainha (M. platanus, Günther, 1880), foi possível concluir que a infecção por $\boldsymbol{A}(\boldsymbol{P}$.) longa ocorreu em $100 \%$ das tainhas adultas, sendo o tecido renal o órgão onde se concentrou o maior número de parasitas. As lesões ocasionadas pelas metacercárias estão restritas aos órgãos parasitados e se apresentam como uma reação do tipo granulomatosa. Os alevinos com comprimento total de 1,8 a $4 \pm 0,5 \mathrm{~cm}$ estavam isentos de infecção.

\section{REFERÊNCIAS}

ALMEIDA DIAS, E.R.; WOICIECHOVSKI, E. Ocorrência da Phagicola longa (Trematoda: Heterophyidae) em mugilídeos e no homem, em Registro e Cananéia, SP. Higiene Alimentar, v.8, n.31, p.43-46, 1994.

ALMEIDA DIAS, E.R. Estudo do ciclo biológico da Phagicola longa (Ransom, 1920) Price, 1932 (Trematoda: Heterophyidae), parasita de peixes mugilídeos e agente de zoonose. São Paulo: USP, 1997. 36p.

ANTUNES, S.A.; ALMEIDA DIAS, E.R. Phagicola longa (Trematoda: Heterophyidae) em mugilídeos estocados resfriados e seu consumo cru em São Paulo - SP. Higiene Alimentar, v.8, n.31, p.41, 1994

ARMAS DE CONROY, G. Observation on diseases and parasites of Mullet alevins Mugil cephalus L. from the Rio Moche Coastal Lagoon of Peru. Journal of Fishes Diseases, v.2, p.513517, 1979.
ARMAS DE CONROY, G. Investigacions sobre la fagicolosis en lisas (Mugilidae) de águas americanas. I Estúdios taxonômicos de Phagicola sp. (Tremátoda: Heterophydae) em mugillideos sudamericanos. Revista Ibérica de Parasitologia, v.46, n.1, p.39-46, 1986.

CHIEFFI, P.P.et al. Human parasitism by Phagicola longa (Trematoda: Heterophyidae) in Cananéia, São Paulo State, Brazil. Revista do Instituto de Medicina Tropical de São Paulo, v.32, n.4, p.285-288, 1990.

CHIEFFI, P.P.et al. Human infection by Phagicola sp. (Trematoda: Heterophyidae) in the municipality of Registro, São Paulo State, Brazil. Journal of Tropical Medicine and Hygiene, v.95, n.4, p.346-348, 1992.

CONROY, G. et al. Diseases and parasites detected in grey mullets (mugilidae) from coastal waters of São Paulo State, Brazil. II. Juvenile silver mullet (Mugil curema Val., 1836). Rivista Italiana di Piscicultura e Ittiopatologia, v.20, n.2, p.74-76, 1985.

CONROY, D.A.et al. Diseases and parasites detected in grey mullets (mugilidae) from coastal waters of São Paulo State, Brazil. III. juvenile silver mullet (Mugil curema Val., 1836) and lebranche mullet (Mugil liza Val. 1836). Rivista Italiana di Piscicultura e Ittiopatologia, v.21A, n.4, p.153-156, 1986.

FONT, W.F. et al. Taxonomy and biology of Phagicola nana (Digenea: Heterophyidae). Transactions of the American Microscopical Society, v.103, n.4, p.408-422, 1984

GODINHO, H.M. et al. Revisão e discussão de trabalhos sobre as espécies do gênero Mugil (Teleostei, Perciformes, mugilidae) da costa brasileira (Lat. $3^{\circ} \mathrm{S}$. $33^{\circ} \mathrm{S}$ ). Boletim do Instituto de Pesca, v.15, n.1, p.67-80, 1988.

HUTTON, R.F. Preliminary notes on trematodes (Heterophydade and Strigeoides) encysted in the heart and flesh of Florida mullet Mugil cephalus L. and Mugil curema Curier \& Valencienes. Bulletin of the Dade County Medical Association, v.2, p.2, 1957.

KNOFF, M. et al. Community ecology of the metazoan parasites of grey mullets, Mugil platanus (Osteichthyes : Mugilidae) from the litoral of the state of Rio de Janeiro, Brazil Revista Brasileira de Biologia, v.57, p.441-454, 1997.

MENEZES, N.A. Guia prático para conhecimento e identificação das tainhas e paratis (Pisces, Mugilidae) do litoral brasileiro. Revista Brasileira de Zoologia, São Paulo, v.2, n.1, p.1-12, 1983

MENEZES, N.A.; FIGUEIREDO, J.L. Manual de peixes marinhos do sudeste do Brasil. Teleostei. São Paulo: Museu de Zoologia, Universidade de São Paulo, 1985. V.4, 105p.

RANZANI-PAIVA, M.J.T. Características hematológicas associadas à biologia e parasitismo em tainha Mugil platanus Günther, 1880 (Osteichthyes, Mugilidae) da região estuarinolagunar de Cananéia - SP (Lat. $25^{\circ} 00^{\circ} \mathrm{S}-$ long. $47^{\circ} \mathrm{SS}$ 'W). Boletim do Instituto de Pesca, v.22, n.1, p.1-22, 1995

SARAIVA, M.E. Estudios de diferentes metodos de conservacion sobre la sobrevivencia de metacercárias de Phagicola longa (Ransom, 1920) Price, 1932 en los tejidos de la Lisa criolla (Mugil curema Val.1836. 1992. 84f. Dissertação (Mestrado em Biologia) - Curso de Pósgraduação em Biologia, Universidad Central de Venezuela Facultad de Ciências, Departamento de Tecnologia de Alimentos. 